\title{
Menthol Enhances Nicotine Reward-Related Behavior by Potentiating Nicotine-Induced Changes in nAChR Function, nAChR Upregulation, and DA Neuron Excitability
}

\author{
Brandon J Henderson',2, Teagan R Wall', Beverley M Henley', Charlene H Kim', Sheri McKinney' and \\ Henry A Lester*,I \\ 'Division of Biology and Biological Engineering, California Institute of Technology, Pasadena, CA, USA; ${ }^{2}$ Department of Biomedical Sciences, \\ Marshall University, Joan C Edwards School of Medicine, Huntington, WV, USA
}

\begin{abstract}
Understanding why the quit rate among smokers of menthol cigarettes is lower than non-menthol smokers requires identifying the neurons that are altered by nicotine, menthol, and acetylcholine. Dopaminergic (DA) neurons in the ventral tegmental area (VTA) mediate the positive reinforcing effects of nicotine. Using mouse models, we show that menthol enhances nicotine-induced changes in nicotinic acetylcholine receptors ( $n A C h R s$ ) expressed on midbrain DA neurons. Menthol plus nicotine upregulates nAChR number and function on midbrain DA neurons more than nicotine alone. Menthol also enhances nicotine-induced changes in DA neuron excitability. In a conditioned place preference (CPP) assay, we observed that menthol plus nicotine produces greater reward-related behavior than nicotine alone. Our results connect changes in midbrain DA neurons to menthol-induced enhancements of nicotine reward-related behavior and may help explain how smokers of menthol cigarettes exhibit reduced cessation rates.

Neuropsychopharmacology (2017) 42, 2285-229I; doi:I0.1038/npp.2017.72; published online 3 May 2017
\end{abstract}

\section{INTRODUCTION}

Menthol cigarettes are used by 1 out of 3 smokers and $>85 \%$ of African-American smokers (McCarthy et al, 1995). Smokers of menthol cigarettes are less likely to quit compared to smokers of non-menthol cigarettes (Ahijevych and Garrett, 2010). Youth smokers of menthol cigarettes are twice as likely to become lifelong smokers compared to youth smokers of non-menthol cigarettes (D'Silva et al, 2012). With e-cigarettes, consumption rates of flavored products (including menthol) are rising, especially among young smokers (Singh et al, 2016). Thus, it is important that we understand how menthol and other tobacco flavorants alter nicotine reward.

VTA neurons containing $\alpha 4, \alpha 6$, and $\beta 2 \mathrm{nAChR}$ subunits $(\alpha 4 \beta 2, \alpha 4 \alpha 6 \beta 2, \alpha 6 \beta 2 \beta 3)$ mediate aspects of nicotine addiction (Tapper et al, 2004; Pons et al, 2008). Upregulation of these nAChRs is considered a biomarker for addiction. Smokers of menthol cigarettes exhibit greater upregulation of brain nAChRs compared to smokers of non-menthol cigarettes (Brody et al, 2013). Menthol enhances nicotine withdrawal (Alsharari et al, 2015) and nicotine intravenous

\footnotetext{
* Correspondence: Professor HA Lester, Division of Biology and Biological Engineering, California Institute of Technology, 1200 East California Boulevard MC I56-29, Pasadena, CA 9| I 25-2900, USA, Tel: +626 395 4946, Fax: +6265648709, E-mail: Lester@Caltech.edu Received 20 December 20 16; revised 28 March 2017; accepted I April 2017; accepted article preview online 12 April 2017
}

self-administration (IVSA) in rats (Wang et al, 2014; Biswas et al, 2016). We have previously reported that menthol alone upregulates $\alpha 4$-containing $\left(\alpha 4^{*}\right)$ and $\alpha 6^{*} \mathrm{nAChRs}$ in the VTA and substantia nigra pars compacta $(\mathrm{SNc})$ (Henderson et al, 2016). Also, menthol alone alters nAChR function on midbrain DA neurons (Henderson et al, 2016). This suggests that menthol directly alters midbrain neurons, in addition to any sensory and metabolic actions that may increase nicotine exposure in the brain.

Here we demonstrate that menthol plus nicotine enhances nicotine reward-related behavior and nicotine's actions on midbrain neurons. We suggest that menthol's ability to enhance nicotine-induced changes in $\mathrm{nAChR}$ function, nAChR number, and DA neuron excitability are important for menthol's enhancement of nicotine reward-related behavior.

\section{MATERIALS AND METHODS}

\section{Menthol Dose Selection}

We estimated the pharmacologically relevant dose of menthol by analogy with nicotine doses used in mouse studies. Typical menthol cigarettes contain $1-5 \mathrm{mg}$ of menthol (Ai et al, 2015) and $\sim 1 \mathrm{mg}$ of nicotine (Rodgman and Perfetti, 2009). Therefore, menthol is 1-5 times that of nicotine. Steady state and peak concentrations of nicotine in human smokers are replicated in mice using 0.4 and $2.0 \mathrm{mg} /$ $\mathrm{kg} / \mathrm{h}$ doses of nicotine, respectively (Matta et al, 2007). CPP 
assays use $0.5 \mathrm{mg} / \mathrm{kg}$ nicotine (Tapper et al, 2004). Assays for in vivo upregulation use $2.0 \mathrm{mg} / \mathrm{kg} / \mathrm{h}$ nicotine (Henderson et al, 2014). We selected $1 \mathrm{mg} / \mathrm{kg}$ and $2 \mathrm{mg} / \mathrm{kg} / \mathrm{h}$ menthol for $\mathrm{CPP}$ and in vivo upregulation assays, respectively. Both dose selections fall within the 1-5 menthol-to-nicotine ratio of menthol cigarettes.

We previously discussed our menthol dose selection for cultured cells and neurons (Henderson et al, 2016). In preliminary assays to determine the concentration of menthol in a mouse brain, our chronic dosing methods ( $2 \mathrm{mg} / \mathrm{kg} / \mathrm{h}$, osmotic pump) produced concentrations of menthol at $0.5-2.5 \mu \mathrm{M}$. Thus, $500 \mathrm{nM}$ menthol is appropriate in studying cultured neurons and cells and is consistent with previous investigations (Henderson et al, 2016).

All material and methods are described in detail in the Supplementary Material.

\section{RESULTS}

\section{Menthol Enhances Nicotine Reward-Related Behavior}

Mice administered with saline or menthol alone (1.0-10 $\mathrm{mg} / \mathrm{kg}$ ) did not exhibit CPP (Figure 1a). Nicotine and menthol plus nicotine produced a significant effect on CPP (Figure 1b, one-way ANOVA, $\mathrm{F}_{(4,83)}=14.3, p<0.001$ ). $0.5 \mathrm{mg} / \mathrm{kg}$ nicotine produced CPP $(p<0.05)$ (Figure $1 \mathrm{~b}$ ), similar to previous observations (Tapper et al, 2004; Henderson et al, 2016). Menthol $(1.0 \mathrm{mg} / \mathrm{kg})$ was administered with either $0.25 \mathrm{mg} / \mathrm{kg}$ or $0.5 \mathrm{mg} / \mathrm{kg}$ nicotine (Figure 1b). In both pairs, menthol plus nicotine produced a significant increase in CPP compared to respective nicotine-only doses $(p<0.05$, Figure $1 \mathrm{~b})$. This suggests that menthol enhances nicotine reward-related behavior and agrees with previous nicotine IVSA assays (Wang et al, 2014; Biswas et al, 2016).

\section{Menthol Plus Nicotine Alters Baseline Midbrain Neuron Firing Frequency}

Using midbrain cultures from tyrosine hydroxylase (TH)eGFP mice, we identified $\mathrm{TH}+/ \mathrm{DA}$ and $\mathrm{TH}-/$ non-DA (putative GABA) neurons. Cultured midbrain neurons were treated with control medium (control), $200 \mathrm{nM}$ nicotine, or $500 \mathrm{nM}$ menthol plus nicotine for 10 days. Control TH+/DA neurons exhibited a firing frequency of $4.1 \pm 0.7 \mathrm{~Hz}$ (Figure 2a1-a3). Drug treatments produced a significant change in firing frequency for $\mathrm{TH}+/ \mathrm{DA}$ (one-way ANOVA, $\mathrm{F}_{(2,61)}=13.07, p<0.001$ ) and $\mathrm{TH}-/$ non-DA neurons (oneway ANOVA, $\left.F_{(2,29)}=8.69, p=0.002\right)$. Nicotine treatment significantly decreased TH+/DA neuron firing frequency $(1.5 \pm 0.3 \mathrm{~Hz}, p<0.005)$. Menthol plus nicotine decreased $\mathrm{TH}$ $+/ \mathrm{DA}$ neuron firing frequency significantly more than nicotine treatment alone $(1.2 \pm 0.2 \mathrm{~Hz}, p<0.05)$. TH - /nonDA neurons exhibited a baseline firing frequency of $8.1 \pm 1.2 \mathrm{~Hz}$ (Figure 2b1-b3). Nicotine treatment increased firing frequency $(13.9 \pm 1.0 \mathrm{~Hz}$, not significant) but menthol plus nicotine increased firing frequency more than nicotine alone $(22.4 \pm 2.1 \mathrm{~Hz}, p<0.005)$.

\section{Menthol Enhances nAChR-Stimulated TH+/DA Neuron Excitability}

Midbrain TH+/DA neurons exhibit transient increases in firing frequency following $\mathrm{nAChR}$ activation, and nicotine's ability to alter tonic and phasic firing of these TH+/DA neurons is necessary for nicotine reward (Mansvelder et al, 2002). Thus, we examined menthol's effect on TH+/DA neuron transient increases in firing frequency following $\mathrm{nAChR}$ activation.

Neurons were treated for 10 days with control, $200 \mathrm{nM}$ nicotine, or $500 \mathrm{nM}$ menthol plus $200 \mathrm{nM}$ nicotine and were recorded in current clamp mode before and after a brief application of ACh (Figure 2c1-c3). Drug treatments produced a significant effect on $\mathrm{TH}+/ \mathrm{DA}$ neuron excitability (one-way ANOVA, $\mathrm{F}_{(2,29)}=9.01, p=0.001$ ). After ACh application, control $\mathrm{TH}+/ \mathrm{DA}$ neurons exhibited a transient, $\sim 2$-fold increase in firing frequency to $8.0 \pm 1.1 \mathrm{~Hz}$ (Figure $2 \mathrm{c} 1-\mathrm{c} 3)$. Nicotine-treated $\mathrm{TH}+/ \mathrm{DA}$ neurons exhibited a $\sim 5$-fold increase in firing frequency, with a maximum of $13.6 \pm 2.5 \mathrm{~Hz}$ (Figure $2 \mathrm{c} 1-\mathrm{c} 3$ ). TH+/DA neurons treated with menthol plus nicotine exhibited an $\sim 8$-fold increase in firing frequency with a maximum of $19.6 \pm 3.1 \mathrm{~Hz}$ (Figure $2 \mathrm{c} 1-\mathrm{c} 3$ ). Thus, we observed that menthol plus nicotine increased firing frequency more than nicotine alone $(p<0.05)$.
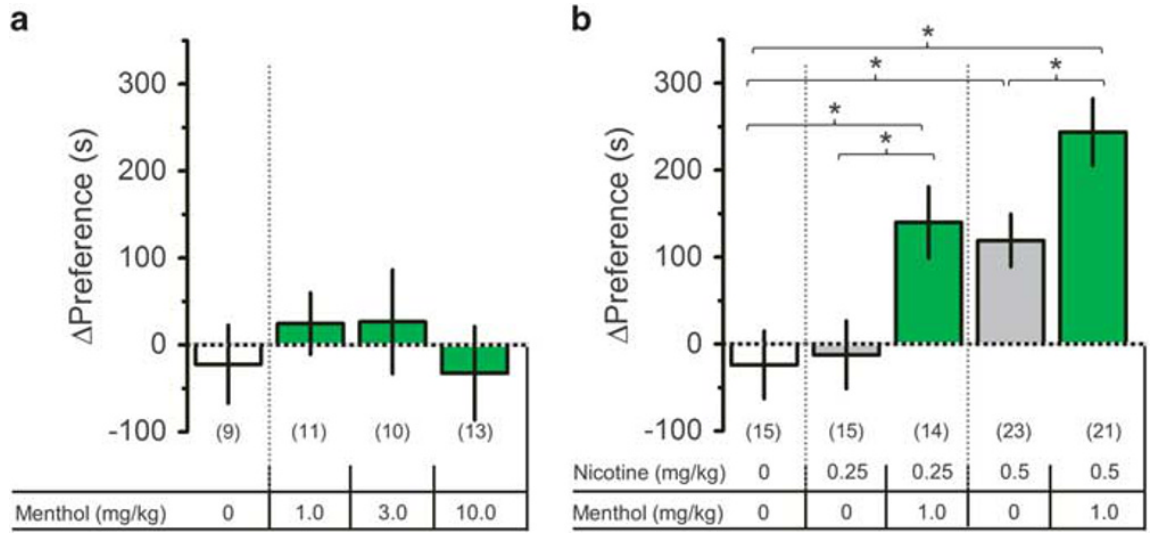

Figure I Menthol alone is not rewarding but enhances nicotine reward-related behavior. (a and b) Mice were administered saline, menthol, nicotine, or menthol plus nicotine at doses indicated. The data are mean \pm SEM. $* 0<0.05$, one-way ANOVA, post hoc Tukey. Numbers in parentheses represent number of mice per group. 
a1

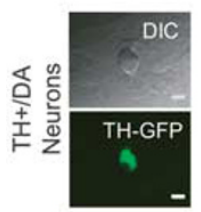

b1

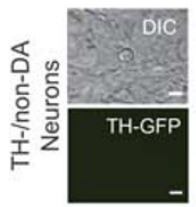

a2

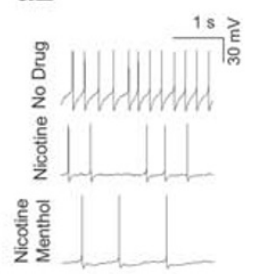

b2

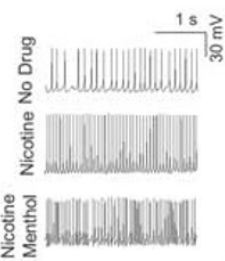

a3

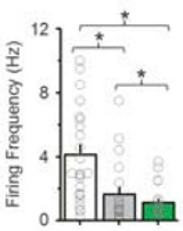

b3

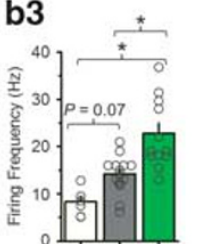

No Drug

Nicotine Treated

Nicotine + Menthol Treated c1
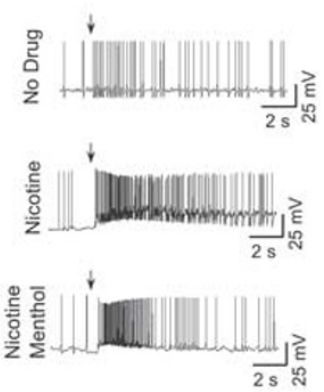

c2

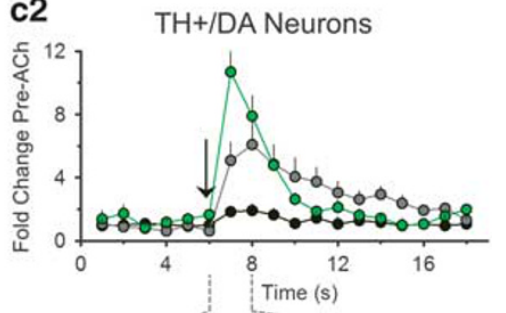

c3

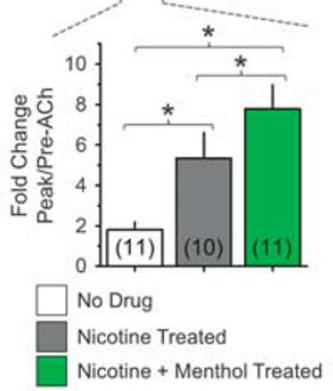

Figure 2 Menthol enhances nicotine-induced changes midbrain neuron firing frequency. (al, bl) Neurons were identified as TH+/DA or TH-/non-DA using TH-eGFP fluorescence. Bars, 20 Mm. (a2-3, b2-3, cl-3) Neurons were treated 10 days with control, 200 nM nicotine, or 500 nM menthol plus 200 nM nicotine and firing frequencies were recorded in current clamp mode. $(\mathrm{a} 3, \mathrm{~b} 3)$ Mean firing frequency of neurons $(n=20-22$ for TH+/DA neurons and $9-13$ for TH-/non-DA neurons). (cl) Current-clamp recordings of TH+/DA neurons before and after ACh puff (I00 ms, $300 \mu M$ at arrows). (c2) Mean firing frequency over time before and after ACh application. (c3) Mean 'peak' firing frequency during $2 \mathrm{~s}$ post-ACh puff. For (cl-3), number of neurons recorded is indicated in parenthesis of (c3). The data are mean \pm SEM: * $p<0.05$, one-way ANOVA, post hoc Tukey.
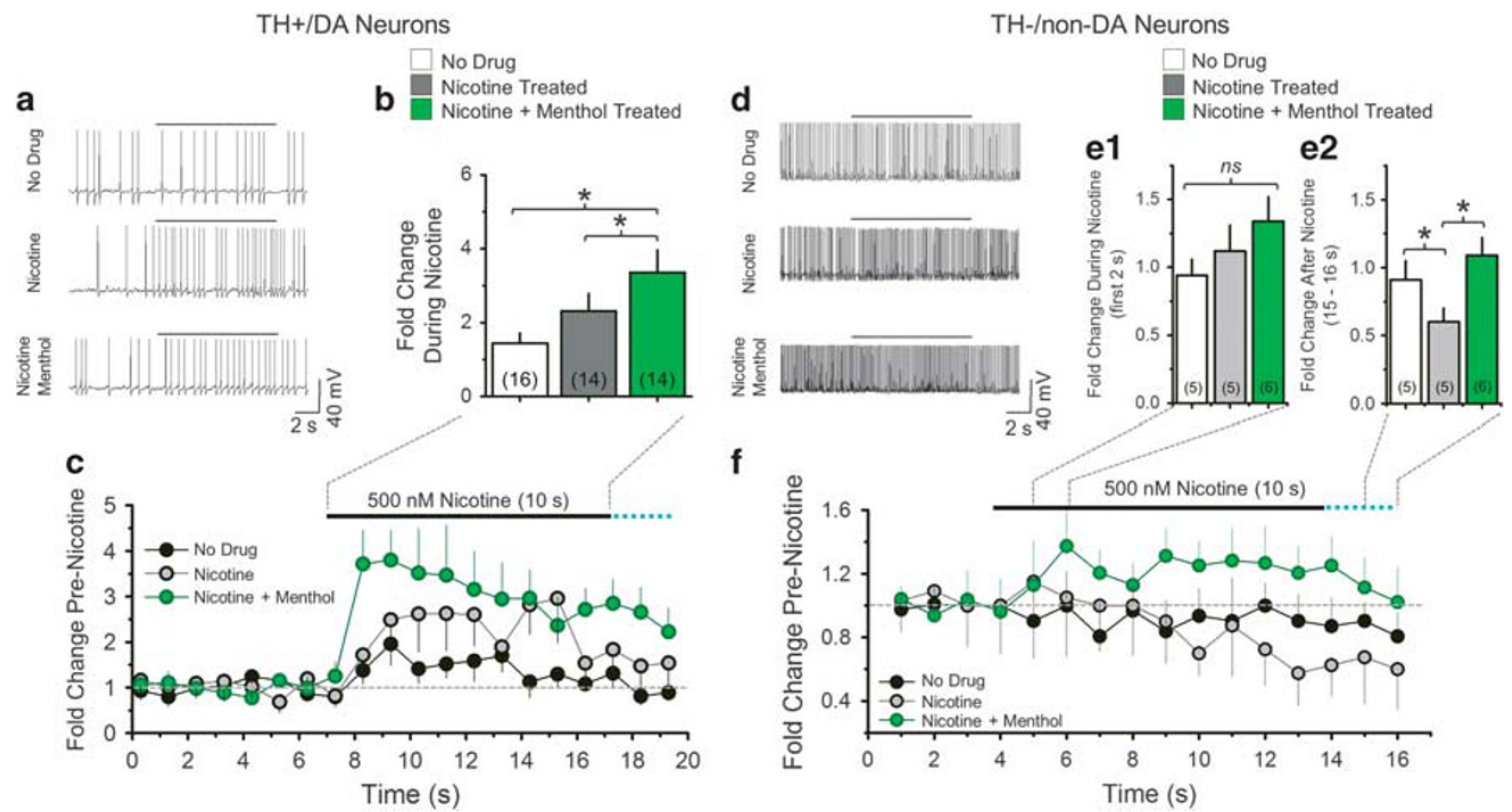

Figure 3 Menthol plus nicotine alters neuron excitability during acute exposure to smoking-relevant nicotine concentrations. Neurons were treated I0 days with control, nicotine, or menthol plus nicotine. ( $\mathrm{a}$ and $\mathrm{d}$ ) Representative current-clamp traces from TH+/DA and TH - /non-DA neurons puffed with nicotine. (b) Mean change in TH+/DA neuron firing frequency during 10 s nicotine applications. (c) and (f), mean firing frequency over time for TH+/DA and $\mathrm{TH}-$ /non-DA neurons, respectively. (el-2) Mean fold-change in TH-/non-DA firing frequency following the first $2 \mathrm{~s}$ of nicotine puff (el) and $2 \mathrm{~s}$ following end of nicotine puff (e2). For (c) and (b), number of individual neurons recorded is indicated in parenthesis in (b). For ( $f$ ) and (el-2), number of individual neurons recorded is indicated in parenthesis in (el-2). The data are mean \pm SEM. *, $p<0.05$, one-way ANOVA, post hoc Tukey. Bars indicate I0 s, $500 \mathrm{nM}$ nicotine application and (c, f) dotted blue lines indicate nicotine remains briefly after the end of puff due to perfusion rate.

In humans, brain nicotine concentrations peak at $\sim 500 \mathrm{nM}$ seconds after a puff on a cigarette (Matta et al, 2007). Accordingly, we investigated how TH+/DA neuron firing frequency changed during a $10 \mathrm{~s}$ exposure to $500 \mathrm{nM}$ nicotine after 10-day treatment with control, nicotine, or menthol plus nicotine (Figure 3). Drug treatment produced a significant effect (one-way ANOVA, $\mathrm{F}_{(2,41)}=7.29, p=0.002$ ). Control TH+/DA neurons exhibited a transient, 1.4-fold increase in firing frequency during nicotine application. Nicotine-treated TH+/DA neurons exhibited a transient, 
2.3-fold increase in firing frequency during nicotine application. TH+/DA neurons treated with menthol plus nicotine exhibited a larger, slowly decaying increase in firing frequency during nicotine application that peaked at 4.0 -fold over baseline and was significantly greater than controltreated $(p<0.005)$ or nicotine-treated $(p<0.05$, Figure 3$) \mathrm{TH}$ $+/$ DA neurons.

We completed similar assays on $\mathrm{TH}-/$ non-DA neurons (Figure 3d-f). Control-treated TH-/non-DA neurons exposed to acute nicotine $(10 \mathrm{~s}, 500 \mathrm{nM})$ exhibited no change in firing frequency. Nicotine-treated $\mathrm{TH}-/$ non-DA neurons exposed to acute nicotine exhibited an initial increase in firing frequency followed by a significant decrease as the nicotine puff continued (Figure $3 \mathrm{e} 1-\mathrm{e} 2$ and $\mathrm{f}$ ) (one-way ANOVA, $\mathrm{F}_{(2,27)}=9.21, p<0.005$, Figure $\left.3 \mathrm{e} 2\right)$. TH $-/$ non-DA neurons treated with menthol plus nicotine exposed to acute nicotine exhibited a non-significant increase in firing frequency that returned to baseline. We have previously reported that acute applications of menthol (up to $1 \mu \mathrm{M}$ ) do not activate nAChRs or potentiate nAChR currents (Henderson et al, 2016). We also stress that $500 \mathrm{nM}$ menthol failed to alter firing frequency or stimulate inward currents in $\mathrm{TH}+/ \mathrm{DA}$ or $\mathrm{TH}-/$ non-DA neurons (Supplementary Figure S1). Thus, the effects we observed result from chronic and not acute actions of menthol.

\section{Menthol Enhances Nicotine-Induced Upregulation of $\alpha 4^{\star}$ But Not $\alpha 6(\text { non }-\alpha 4)^{\star}$ nAChRs}

Midbrain DA neurons contain $\alpha 4 \beta 2$ (non- $\alpha 6)^{*}, \alpha 6 \beta 2$ (non$\alpha 4)^{\star}$, and $\alpha 4 \alpha 6 \beta 2^{\star}$ nAChRs, while midbrain GABA neurons contain $\alpha 4 \beta 2$ (non $-\alpha 6)^{*}$ nAChRs (Champtiaux et al, 2003). These $\mathrm{nAChR}$ subtypes are most sensitive to nicotine and are vital for nicotine reward (Pons et al, 2008). To study $\alpha 4^{*}$ and $\alpha 6^{*}$ nAChR upregulation, we used $\alpha 4$-mCherry $\alpha 6$-GFP mice that were treated for 10 days with vehicle, nicotine $(2 \mathrm{mg} / \mathrm{kg} /$ $\mathrm{h}$ ), or menthol plus nicotine $(2 \mathrm{mg} / \mathrm{kg} / \mathrm{h}$, each). Similar to previous studies (Henderson et al, 2014, 2016), increases in integrated density of GFP or mCherry fluorescence was used to determine change in $\mathrm{nAChR}$ number. In midbrain, $\alpha 6^{*}$ nAChRs are selectively expressed in DA neurons (Mackey et al, 2012), so DA neurons of the SNc and VTA were identified by the presence of $\alpha 6$-GFP fluorescence (Figure $4 \mathrm{a}$ and $\mathrm{b} 1-\mathrm{b} 2)$.

We observed a significant effect of drug treatment on $\alpha 4$-mCherry and $\alpha 6$-GFP fluorescence intensity in the VTA (one-way ANOVA: $\mathrm{F}_{(2,12)}=24.1, p<0.001$ and $\mathrm{F}_{(2,12)}=5.43$, $p=0.017, \alpha 4$-mCherry and $\alpha 6-\mathrm{GFP}$, respectively) and $\mathrm{SNc}$ (one-way ANOVA: $\mathrm{F}_{(2,12)}=4.14, p=0.043$ and $\mathrm{F}_{(2,12)}=7.87$, $p=0.007, \alpha 4$-mCherry and $\alpha 6$-GFP respectively) and substantia nigra pars reticulata $(\mathrm{SNr})$ (one-way ANOVA: $\mathrm{F}_{(2,12)}=8.68, \quad p=0.005, \alpha 4$-mCherry). Nicotine treatment robustly increased $\alpha 4^{\star} \mathrm{nAChR}$ number in VTA DA neurons and SNr GABA neurons (Figure 4c1-c3). Menthol plus nicotine produced an increase in $\alpha 4^{*} \mathrm{nAChRs}$ in these same regions that was significantly greater than nicotine alone $(p<0.05)$. In SNc DA neurons, $\alpha 4^{*} \mathrm{nAChR}$ number was increased by nicotine $(p<0.05)$ and the addition of menthol yielded no difference. As observed previously (Henderson et al, 2014), nicotine increased $\alpha 6^{*} \mathrm{nAChR}$ number in VTA and SNc DA neurons (Figure 4c1-c2). In VTA neurons, menthol plus nicotine increased $\alpha 6^{*}$ nAChR number but was not different from nicotine treatment alone. In SNc DA neurons, menthol plus nicotine did not increase $\alpha 6^{*}$ nAChR number. These data suggest that menthol enhances only $\alpha 4^{*}$ nAChR upregulation in VTA DA and $\mathrm{SNr}$ GABA neurons, and does not enhance $\alpha 6^{*} \mathrm{nAChR}$ upregulation.

We observed a similar trend in functional upregulation of nAChRs: nicotine alone upregulates $\alpha 4^{*}$ and $\alpha 6^{*} \mathrm{nAChR}$ function, but menthol plus nicotine provides a further increase in only $\alpha 4^{*}$ nAChR function (Supplementary Figure S2). In vitro, we observed that menthol enhanced nicotine-induced upregulation of $\alpha 4^{*}$ and not $\alpha 6^{*}$ nAChRs (Supplementary Figure S3) and the upregulated $\alpha 4^{\star}$ nAChRs were of the high-sensitivity stoichiometry (Supplementary Figure S4). These data further suggest that menthol may selectively enhance upregulation of $\alpha 4^{*}$ and not $\alpha 6^{*}$ nAChRs. Using RNA-seq, we found that $\mathrm{nAChR}$ upregulation by menthol plus nicotine was not accompanied by any changes in mRNA (Supplementary Figure S3G). Full descriptions of these results can be found in the Supplementary Results section of the Supplementary Material.

\section{Menthol Enhances Nicotine-Induced Upregulation of $\alpha 4 \alpha 6^{*}$ nAChRs}

Using pixel-based FRET methods (Henderson et al, 2014), we identified regions where $\alpha 4$-mCherry and $\alpha 6$-GFP nAChR subunits co-assembled to form $\alpha 4 \alpha 6^{*}$ nAChRs (Figure 4b1-b2). Drug treatment produced a significant effect on $\alpha 4 \alpha 6^{*}$ nAChR number in the VTA (one-way ANOVA: $\mathrm{F}_{(2,12)}=14.4, p<0.001$ ) and SNc (one-way ANOVA: $\left.\mathrm{F}_{(2,12)}=8.23, p=0.006\right)$. In the VTA, $\alpha 4 \alpha 6^{*} \mathrm{nAChR}$ number did not significantly increase following nicotine treatment, but menthol plus nicotine significantly increased $\alpha 4 \alpha 6^{*}$ nAChR number (Figure $4 \mathrm{c} 1$ ). In the SNc, nicotine and menthol plus nicotine increased $\alpha 4 \alpha 6^{\star} \mathrm{nAChR}$ number to a similar extent (Figure 4c2).

Next, we examined whether menthol potentiated nicotineinduced $\mathrm{nAChR}$ upregulation on VTA DA neurons under the same drug exposure conditions as our CPP assays. $\alpha 4$ mCherry $\alpha 6$-GFP mice were given injections of saline, nicotine, or menthol plus nicotine, with dosing identical to CPP assays (presented in Figure 1). Because VTA DA neurons are critical for nicotine reward (Pons et al, 2008), we examined only VTA DA neurons (Figure 4d1-d3). We observed a significant effect on $\alpha 4^{*}$ nAChRs $\left(\mathrm{F}_{(2,15)}=3.90\right.$, $p=0.04$, Figure $4 \mathrm{~d} 1$ ). Nicotine produced $20.1 \%$ increase in $\alpha 4^{\star}$ nAChR number (not significant), while menthol plus nicotine produced a $41.3 \%$ increase $(p<0.05)$. We observed no change in $\alpha 6^{*}$ nAChR number (Figure $4 \mathrm{~d} 2$ ). These lessrobust observations with alternating daily injections, compared to osmotic pumps, agreed with previous observations of $\mathrm{nAChR}$ upregulation.

We observed a significant effect on $\alpha 4 \alpha 6^{*} \mathrm{nAChR}$ number $\left(\mathrm{F}_{(2,15)}=15.7, p<0.001\right.$, Figure $\left.4 \mathrm{~d} 3\right)$. Nicotine produced a $54.7 \%$ increase $(p<0.05)$, while menthol plus nicotine produced a $117.6 \%$ increase $(p<0.005)$. The increased $\alpha 4 \alpha 6^{*}$ nAChR number in VTA neurons is accounted for by an increased number of FRET pixels, rather than by increased fluorescence intensity. This was consistent in both osmotic pump and injected preparations. 
a

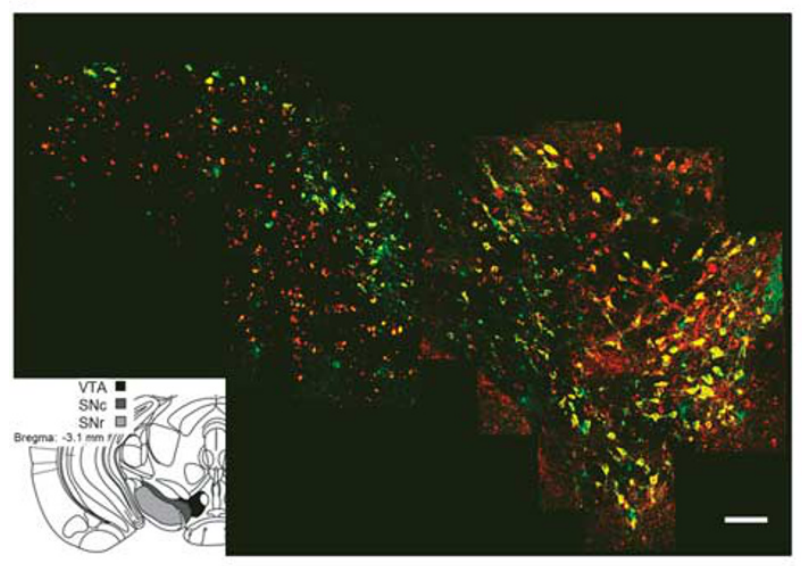

c1

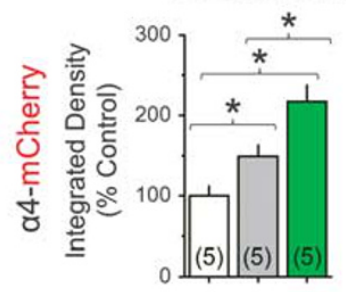

SNc Neurons

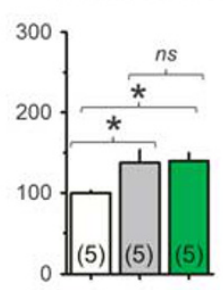

c2
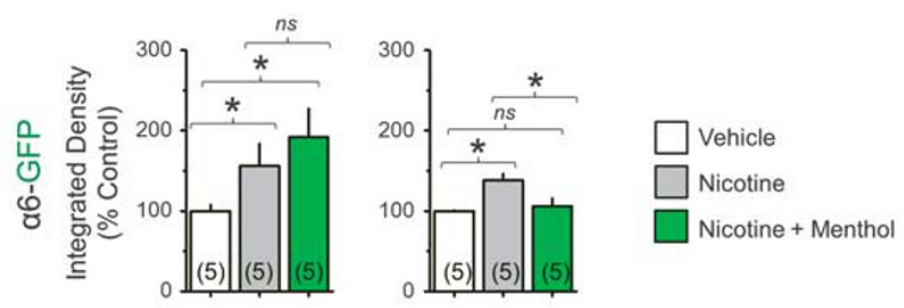

c3

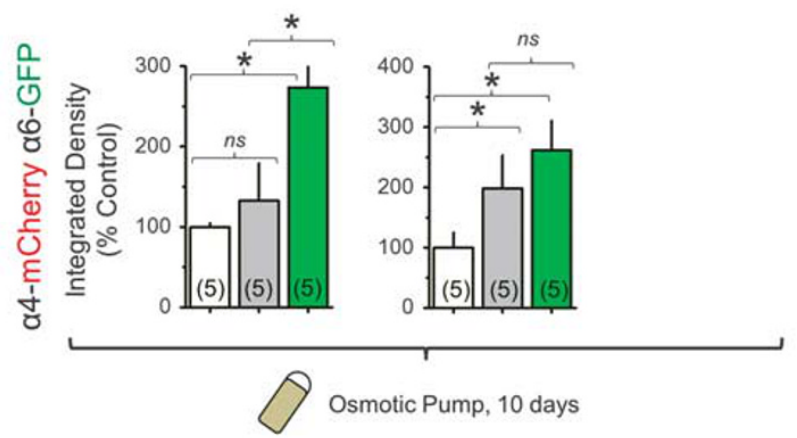

b1

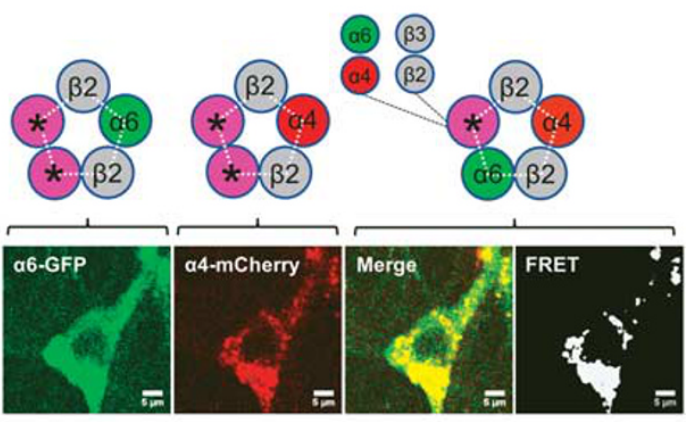

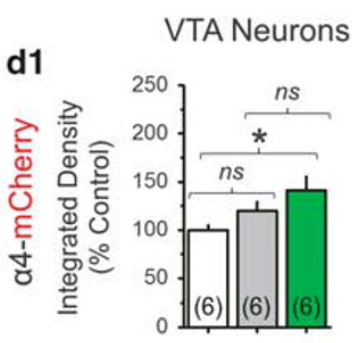

d2

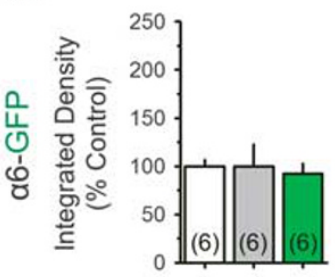

d3

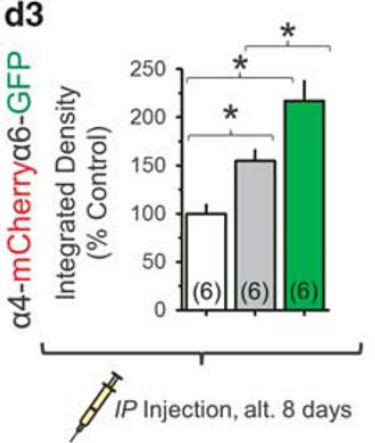

Figure 4 Menthol enhances nicotine-induced upregulation. (a) Representative coronal slice (bregma - 3. I) with $\alpha 4$-mCherry $\alpha 6$-GFP-labeled neurons in the VTA, SNc, and SNr. Bar, $100 \mu \mathrm{m}$. (b I) Potential assemblies of midbrain nAChRs revealed by GFP and mCherry fluorescence. The subunits indicated by * are uncertain $(\alpha 4, \alpha 6, \beta 2$, or $\beta 3$ ). (b2) Representative $\alpha 4$-mCherry $\alpha 6$-GFP* neurons. (cl-3) $\alpha 4$-mCherry*, $\alpha 6$-GFP*, or $\alpha 4 \alpha 6 *$ nAChR-integrated density. The data are mean \pm SEM, normalized to vehicle. (cl-3) Chronic treatments were 10 days: vehicle, $2 \mathrm{mg} / \mathrm{kg} / \mathrm{h}$ nicotine, or $2 \mathrm{mg} / \mathrm{kg} / \mathrm{h}$ nicotine with $2 \mathrm{mg} / \mathrm{kg} / \mathrm{h}$ menthol. $(\mathrm{dl}-3)$ Mice were given drug dosing identical to CPP assays. Number of mice for each treatment is indicated in parenthesis. $* 2<0.05$, one-way ANOVA, post hoc Tukey.

\section{DISCUSSION}

Individual deletions of $\alpha 4, \alpha 6$, or $\beta 2 \mathrm{nAChR}$ subunits prevent self-administration of nicotine in mice; and selective re-expression of these deleted subunits in the VTA (not $\mathrm{SNc}$ or $\mathrm{SNr}$ ) re-instates self-administration (Pons et al, 2008). Selective activation of $\alpha 6 \beta 2^{\star}$ or $\alpha 4 \beta 2^{\star} \mathrm{nAChRs}$ by smoking-relevant concentrations of nicotine stimulates depolarization and elevates firing frequency of VTA DA neurons (Liu et al, 2012; Engle et al, 2013). Both $\alpha 4$ and $\alpha 6$ nAChR subunits are necessary for this as preparations lacking either $\alpha 4$ or $\alpha 6 \mathrm{nAChR}$ subunits failed to stimulate depolarization or elevate VTA DA neuron firing in response to nicotine. Together, these data highlight VTA $\alpha 4 \alpha 6 \beta 2^{*}$ $\mathrm{nAChRs}$ as the primary targets of smoking-relevant concentrations of nicotine. 
a1

\section{Saline}

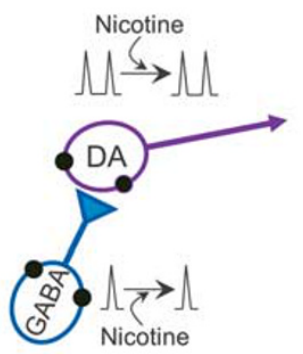

a2 Chronic Nicotine

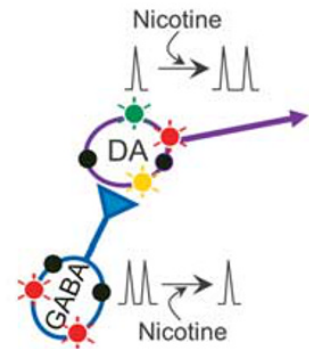

a3

Chronic Menthol + Nicotine

\footnotetext{
- Baseline $a 4^{\star}, a 6^{\star}$, or $\alpha 4 a 6^{*} n A C h R$

Upregulated $a 4^{*} \mathrm{nAChR}$

Upregulated $a 6^{\star} \mathrm{nAChR}$

Upregulated $a 4 a 6^{*} \mathrm{nAChR}$
}

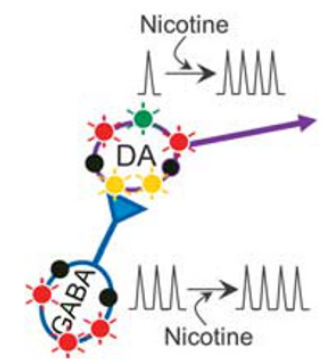

Figure 5 Summary. Simplified circuit diagram showing GABAergic neurons (blue) projecting to VTA DA neurons (purple). Arrows indicate acute applications of nicotine and its effect on firing frequency. See discussion for complete description.

We observed a significant increase in $\alpha 4 \alpha 6 \beta 2^{*} \mathrm{nAChR}$ number following menthol plus nicotine treatment, greater than the increase observed with nicotine alone (Figure 4c3 and $\mathrm{d} 3$ ). In assays using alternating daily injections, we observed little or no increase in total $\alpha 4^{*}$ or $\alpha 6^{*}$ nAChRs (Figure $4 \mathrm{~d} 1-\mathrm{d} 2$ ). Considering the increase in $\alpha 4 \alpha 6^{*} \mathrm{nAChRs}$, detected primarily by an increase in FRET pixels, this suggests that nicotine and menthol plus nicotine selectively upregulate the rather small, highly nicotine-sensitive subpopulation of nAChRs that contain both $\alpha 4$ and $\alpha 6$ subunits. Note that our brain slice microscopy method measures both intracellular and plasma membrane nAChRs and is not a direct measurement of functional nAChRs.

If $\alpha 4 \alpha 6 \beta 2^{*}$ nAChRs are the primary targets of smokingrelevant concentrations of nicotine, their enhanced upregulation by menthol plus nicotine may underlie the enhancement in reward-related behavior (Figure 1b). The enhancement in TH+/DA-neuron firing frequency that we observed with menthol plus nicotine (Figure 3c) also supports this. Liu et al (2012) found that $300 \mathrm{nM}$ nicotine applications elevated VTA DA neuron firing in a biphasic manner where $\alpha 4$ (non- $\alpha 6) \beta 2^{*}$ nAChRs mediated a rapid, desensitizing response and $\alpha 4 \alpha 6 \beta 2^{*}$ mediated a sustained elevation in firing. We did observe robust, sustained increases in TH+/DA-neuron firing with similar nicotine applications. This may be attributed to the upregulated $\alpha 4 \alpha 6 \beta 2^{*}$ nAChRs. GABAergic inputs on VTA neurons also play an important role in nicotine's actions. Following chronic exposure to nicotine, $\alpha 4^{*}$ nAChRs are upregulated on SNr GABAergic neurons (Figure 4)(Nashmi et al, 2007). Acute nicotine exposure enhances GABAergic activity transiently, followed by sustained depression due to the upregulated $\alpha 4^{*} \mathrm{nAChRs}$ ' rapid desensitization, leading to increased DA neuron excitability (Mansvelder et al, 2002). In $\mathrm{TH}-$ /non-DA neurons, we did measure transient increases in firing, followed by a maintained depression in activity (Figure 3f) in agreement with Mansvelder et al. TH-/nonDA neurons treated with menthol plus nicotine did not decrease in firing frequency during nicotine applications. We have previously observed that menthol (alone) reduces $\alpha 4 \beta 2^{*}$ nAChR desensitization (Henderson et al, 2016). This may explain how TH-/non-DA neurons may fail to desensitize during nicotine applications as they have only $\alpha 4$ (non- $\alpha 6) \beta 2^{*}$ nAChRs. These observations are summarized in Figure 5.

Comparing menthol alone (Henderson et al, 2016) to menthol plus nicotine (studied here), we observe a distinct difference. Menthol alone upregulates low-sensitivity $\alpha 4^{*}$ and $\alpha 6^{*}$ nAChRs, suppresses DA neuron excitability, and suppresses nicotine reward-related behavior. Menthol plus nicotine enhances DA neuron excitability and nicotine reward-related behavior (Figures 1,2,3). The likely molecular basis is that menthol plus nicotine increases the number of high-sensitivity $\alpha 4^{*}$ and $\alpha 6^{*}$ nAChRs, but menthol alone upregulates low-sensitivity $\alpha 4^{*}$ and $\alpha 6^{*}$ nAChRs (Supplementary Figure S4 and Henderson et al, 2016).

We note that smokers experience odorant and tastant effects of menthol. It was shown that menthol decreases oral nicotine aversion in mice through a TRPM8-dependent mechanism (Fan et al, 2016). We stress that our results presented here use a drug exposure paradigm that avoids tastant effects and the neurons in our preparations (slices or cultures) do not contain TRPM8 receptors (Henderson et al, 2016). We suggest that tastant and sensory effects act in addition to the direct, neuron-mediated effects we observed.

We provide a cellular basis for how menthol may enhance nicotine reward-related behavior. Our findings, combined with the knowledge that menthol may enhance nicotine withdrawal (Alsharari et al, 2015) and nicotine IVSA (Wang et al, 2014; Biswas et al, 2016), may provide insight into why smokers of menthol cigarettes report lower quit rates.

\section{FUNDING AND DISCLOSURE}

This work was supported by fundings from the National Institutes of Health (NIH) (DA040047, DA033721, DA036061, DA037161, and DA037743).The authors declare no conflict of interest. 


\section{REFERENCES}

Ahijevych K, Garrett BE (2010). The role of menthol in cigarettes as a reinforcer of smoking behavior. Nicotine Tob Res 12(Suppl 2): S110-S116.

Ai J, Taylor KM, Lisko JG, Tran $\mathrm{H}$, Watson $\mathrm{CH}$, Holman MR (2015). Menthol content in US marketed cigarettes. Nicotine Tob Res 18: 1575-1580.

Alsharari SD, King JR, Nordman JC, Muldoon PP, Jackson A, Zhu AZX et al (2015). Effects of menthol on nicotine pharmacokinetic, pharmacology and dependence in mice. PloS ONE 10: e0137070.

Biswas L, Harrison E, Gong Y, Avusula R, Lee J, Zhang M et al (2016). Enhancing effect of menthol on nicotine self-administration in rats. Psychopharmacology 233: 3417-3427.

Brody A, Mukhin A, La Charite J, Ta K, Farahi J, Sugar C et al (2013). Up-regulation of nicotinic acetylcholine receptors in menthol cigarette smokers. Int J Neuropsychopharmacol 16: 957-966.

CDC (2016). Tobacco use among middle and high school students United States, 2011 - 2015. MMWR Morb Mortal Wkly Rep 65: 361-367.

Champtiaux N, Gotti C, Cordero-Erausquin M, David DJ, Przybylski C, Lena C et al (2003). Subunit composition of functional nicotinic receptors in dopaminergic neurons investigated with knock-out mice. J Neurosci 23: 7820-7829.

D'Silva J, Boyle RG, Lien R, Rode P, Okuyemi KS (2012). Cessation outcomes among treatment-seeking menthol and nonmenthol smokers. Am J Prev Med 43: S242-S248.

Engle SE, Shih PY, McIntosh JM, Drenan RM (2013). Alpha4alpha6beta $2^{*}$ nicotinic acetylcholine receptor activation on ventral tegmental area dopamine neurons is sufficient to stimulate a depolarizing conductance and enhance surface AMPA receptor function. Mol Pharmacol 84: 393-406.

Fan L, Balakrishna S, Jabba SV, Bonner PE, Taylor SR, Picciotto MR et al (2016). Menthol decreases oral nicotine aversion in C57BL/6 mice through a TRPM8-dependent mechanism. Tob Control 0: $1-5$.

Henderson BJ, Srinivasan R, Nichols WA, Dilworth CN, Gutierrez DF, Mackey ED et al (2014). Nicotine exploits a COPI-mediated process for chaperone-mediated up-regulation of its receptors. J Gen Physiol 143: 51-66.

Henderson BJ, Wall T, Henley BM, Kim CH, Nichols WA, Moaddel $\mathrm{R}$ et al (2016). Menthol alone upregulates midbrain nAChRs, alters nAChR sybtype stoichiometry, alters dopamine neuron firing frequency, and prevents nicotine reward. J Neurosci 36: $2957-2974$.
Liu L, Zhao-Shea R, McIntosh JM, Gardner PD, Tapper AR (2012). Nicotine persistently activates ventral tegmental area dopaminergic neurons via nicotinic acetylcholine receptors containing alpha4 and alpha6 subunits. Mol Pharmacol 81: 541-548.

Mackey ED, Engle SE, Kim MR, O'Neill HC, Wageman CR, Patzlaff NE et al (2012). $\alpha 6^{*}$ nicotinic acetylcholine receptor expression and function in a visual salience circuit. J Neurosci 32: 10226-10237.

Mansvelder HD, Keath JR, McGehee DS (2002). Synaptic mechanisms underlie nicotine-induced excitability of brain reward areas. Neuron 33: 905-919.

Matta SG, Balfour DJ, Benowitz NL, Boyd RT, Buccafusco JJ, Caggiula AR et al (2007). Guidelines on nicotine dose selection for in vivo research. Psychopharm 190: 269-319.

McCarthy WJ, Caskey NH, Jarvik ME, Gross TM, Rosenblatt MR, Carpenter C (1995). Menthol vs nonmenthol cigarettes: effects on smoking behavior. Am J Public Health 85: 67-72.

Nashmi R, Xiao C, Deshpande P, McKinney S, Grady SR, Whiteaker $\mathrm{P}$ et al (2007). Chronic nicotine cell specifically upregulates functional $\alpha 4^{*}$ nicotinic receptors: basis for both tolerance in midbrain and enhanced long-term potentiation in perforant path. J Neurosci 27: 8202-8218.

Pons S, Fattore L, Cossu G, Tolu S, Porcu E, McIntosh JM et al (2008). Crucial role of $\alpha 4$ and $\alpha 6$ nicotinic acetylcholine receptor subunits from ventral tegmental area in systemic nicotine selfadministration. J Neurosci 28: 12318-12327.

Rodgman A, Perfetti TA (2009). The Chemical Components of Tobacco and Tobacco Smoke. CRC Press: Boca Raton, FL, USA.

Tapper AR, McKinney SL, Nashmi R, Schwarz J, Deshpande P, Labarca C et al (2004). Nicotine activation of $\alpha 4^{*}$ receptors: sufficient for reward, tolerance and sensitization. Science 306: 1029-1032.

Wang T, Wang B, Chen H (2014). Menthol facilitates the intravenous self-administration of nicotine in rats. Front Behav Neurosci 8: 437.

(i) $(-)$ This work is licensed under a Creative Commons Attribution-NonCommercial-NoDerivs $\quad 4.0$ International License. The images or other third party material in this article are included in the article's Creative Commons license, unless indicated otherwise in the credit line; if the material is not included under the Creative Commons license, users will need to obtain permission from the license holder to reproduce the material. To view a copy of this license, visit http://creativecommons.org/licenses/by-nc-nd/4.0/

(C) The Author(s) 2017

Supplementary Information accompanies the paper on the Neuropsychopharmacology website (http://www.nature.com/npp) 